\title{
Low encoding frequencies accurately quantify cardiac mechanics while minimizing phase wrapping in 2D cine DENSE with through-plane dephasing
}

\author{
Jonathan D Grabau ${ }^{1 *}$, Gregory J Wehner ${ }^{1}$, Jonathan D Suever ${ }^{1}$, Christopher M Haggerty ${ }^{1}$, Linyuan Jing ${ }^{1}$, \\ David Powell ${ }^{2}$, Sean M Hamlet ${ }^{1}$, Xiaodong Zhong ${ }^{3}$, Frederick H Epstein ${ }^{4}$, Brandon K Fornwalt ${ }^{1,2}$
}

From 18th Annual SCMR Scientific Sessions

Nice, France. 4-7 February 2015

\section{Background}

Displacement Encoding with Stimulated Echoes (DENSE) encodes displacement into the phase of the MR signal to quantify cardiac mechanics. The encoding frequency $\left(k_{\mathrm{e}}\right)$ links myocardial displacement to phase. Studies with 2D cine DENSE have used $\mathrm{k}_{\mathrm{e}}$ of 0.10 cycles $/ \mathrm{mm}$, which is high enough to remove the stimulated anti-echo from the sampled k-space and is partially responsible for dephasing the blood signal. This $\mathrm{k}_{\mathrm{e}}$ leads to wrapping in the phase images and causes intra-voxel dephasing. With the advent of through-plane dephasing, the unwanted echo can be removed without relying on high $\mathrm{k}_{\mathrm{e}}$. This may allow the use of lower $k_{\mathrm{e}}$ to simplify post-processing and increase SNR. Low $k_{e}$, however, may be less sensitive to displacement and result in inaccurate measures of cardiac mechanics. We hypothesized that $\mathrm{k}_{\mathrm{e}}$ below 0.10 cycles $/ \mathrm{mm}$ will 1 ) provide accurate measures of cardiac mechanics, 2) minimize phase wrapping, 3) dephase the blood signal, and 4) improve SNR.

\section{Methods}

Spiral cine DENSE was obtained on 10 healthy subjects and 5 patients with a history of heart disease on a 3T Siemens Tim Trio. For each subject, a mid-ventricular short-axis slice was acquired 5 times with respiratory navigation using a range of encoding frequencies: 0.02 , $0.04,0.06,0.08$, and 0.10 cycles $/ \mathrm{mm}$. The acquisition with 0.10 cycles $/ \mathrm{mm}$ was repeated to assess inter-test reproducibility. Other DENSE parameters included: 6

'Pediatrics, University of Kentucky, Lexington, KY, USA

Full list of author information is available at the end of the article spiral interleaves, $2.4 \times 2.4 \times 8 \mathrm{~mm}$ voxel size, $1.08 / 17 \mathrm{~ms}$ TE/TR, constant $20^{\circ}$ flip angle, CSPAMM echo suppression, and through-plane dephasing of 0.08 cycles $/ \mathrm{mm}$. Twist, circumferential strain, and radial strain were compared between acquisitions employing different $k_{\mathrm{e}}$ using Bland-Altman analyses, coefficient of variation $(\mathrm{CoV})$, and paired $\mathrm{t}$-tests. The percentage of wrapped pixels in the phase images at end-systole was calculated for each $\mathrm{k}_{\mathrm{e}}$. The magnitude of the blood pool signal was measured through the cardiac cycle to follow dephasing. SNR was calculated at end-systole to assess intra-voxel dephasing.

\section{Results}

Figure 1 contains end-systolic images from a representative subject. Negligible differences were seen in the strains and twist for all $\mathrm{k}_{\mathrm{e}}$ between 0.04 and 0.10 cycles/ $\mathrm{mm}$ (Table 1). These differences were of the same magnitude as the inter-test differences. For 0.02, 0.04, $0.06,0.08$, and 0.10 cycles $/ \mathrm{mm}: 1$ ) the percentage of wrapped pixels in the phase images at end-systole was $0,0,6,19$, and $35 \%, 2$ ) the percent of blood pool signal remaining $68 \mathrm{~ms}$ after encoding was $30,28,25,24$, and $22 \%$, and 3) the mean SNR at end-systole was 26,26 , 26,25 , and 24 , respectively.

\section{Conclusions}

For 2D cine DENSE with through-plane dephasing, the encoding frequency can be lowered to 0.04 cycles $/ \mathrm{mm}$ without causing changes in measures of twist or strain. The amount of wrapping and reliance on un-wrapping algorithms can be substantially reduced with this lower 


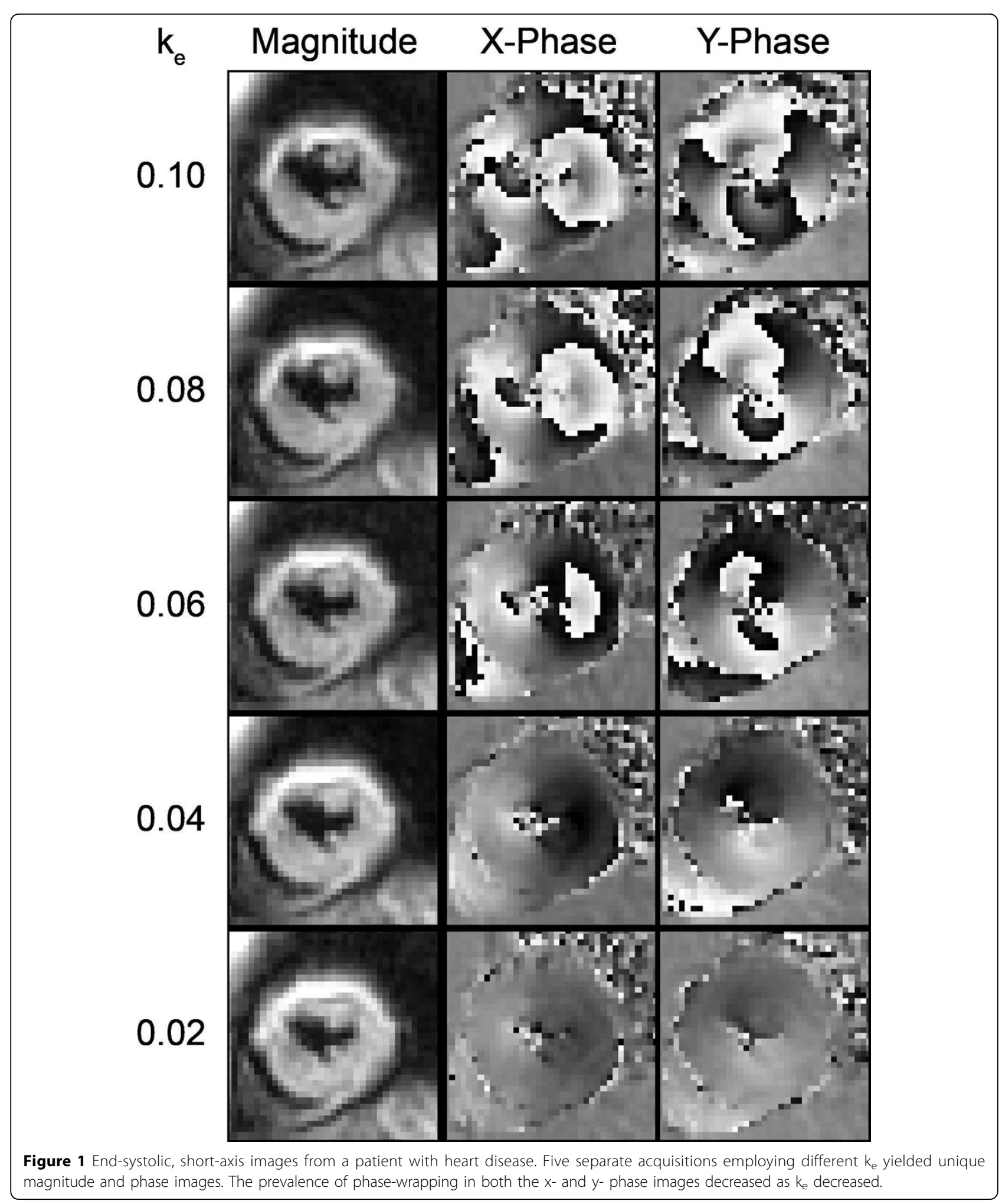


Table 1 Summary statistics (all 15 subjects) showing good agreement for encoding frequency between 0.04 and 0.10 cycles $/ \mathrm{mm}$. Larger biases, $95 \%$ LOA, and CoV were observed for encoding frequency of $0.02 \mathrm{cycles} / \mathrm{mm}$.

\begin{tabular}{|c|c|c|c|c|c|c|c|c|c|c|c|c|}
\hline \multirow[t]{2}{*}{$E\left(k_{e}\right) *$} & \multicolumn{4}{|c|}{ Circumferential Strain } & \multicolumn{4}{|c|}{ Radial Strain } & \multicolumn{4}{|c|}{ Twist (Degrees) } \\
\hline & Bias & $95 \%$ LOA & Mean CoV & p-value & Bias & $95 \%$ LOA & Mean CoV & $p$-value & Bias & $95 \%$ LOA & Mean CoV & $p$-value \\
\hline$E(0.10)-E(0.02)$ & $-1.9 \%$ & $\pm 5.3 \%$ & $10 \%$ & $0.02^{* *}$ & $3.1 \%$ & $\pm 21.9 \%$ & $22 \%$ & 0.31 & -0.50 & \pm 1.89 & $12 \%$ & 0.07 \\
\hline$E(0.10)-E(0.04)$ & $0.0 \%$ & $\pm 3.2 \%$ & $4 \%$ & 1.00 & $-1.0 \%$ & $\pm 13.5 \%$ & $10 \%$ & 0.57 & -0.02 & \pm 1.26 & $7 \%$ & 0.91 \\
\hline$E(0.10)-E(0.06)$ & $0.6 \%$ & $\pm 2.9 \%$ & $4 \%$ & 0.15 & $0.6 \%$ & $\pm 11.2 \%$ & $10 \%$ & 0.69 & -0.19 & \pm 0.79 & $4 \%$ & 0.09 \\
\hline$E(0.10)-E(0.08)$ & $0.3 \%$ & $\pm 3.0 \%$ & $4 \%$ & 0.45 & $-1.8 \%$ & $\pm 9.7 \%$ & $9 \%$ & 0.19 & -0.05 & \pm 0.71 & $4 \%$ & 0.59 \\
\hline Inter-test & $-0.3 \%$ & $\pm 2.0 \%$ & $3 \%$ & 0.23 & $0.4 \%$ & $\pm 12.1 \%$ & $10 \%$ & 0.81 & 0.00 & \pm 0.93 & $5 \%$ & 0.99 \\
\hline
\end{tabular}

*Represents peak strain and twist measured using a particular encoding frequency.

**Statistical significance between peak measures of mechanics using paired-sample t-test at significance level $\alpha=0.05$.

***LOA - Limits of Agreement, CoV - Coefficient of Variation.

value. The use of lower $k_{e}$ marginally decreases the rate of blood pool dephasing and provides small improvements in SNR.

\section{Funding}

This work was supported by a National Institutes of Health (NIH) Director's Early Independence Award (DP5 OD-012132), NIH grant number T32 HL-072743, and NIH grant numbers UL1TR000117 and KL2 RR033171 from the National Center for Research Resources and the National Center for Advancing Translational Sciences. The content is solely the responsibility of the authors and does not necessarily represent the official views of $\mathrm{NIH}$.

\section{Authors' details}

${ }^{1}$ Pediatrics, University of Kentucky, Lexington, KY, USA. ${ }^{2}$ Biomedical Engineering, University of Kentucky, Lexington, KY, USA. ${ }^{3} M R$ R\&D Collaborations, Siemens Healthcare, Atlanta, GA, USA. ${ }^{4}$ Biomedical Engineering, University of Virgina, Charlottesville, VA, USA.

Published: 3 February 2015
doi:10.1186/1532-429X-17-S1-0118

Cite this article as: Grabau et al: Low encoding frequencies accurately quantify cardiac mechanics while minimizing phase wrapping in $2 \mathrm{D}$ cine DENSE with through-plane dephasing. Journal of Cardiovascular Magnetic Resonance 2015 17(Suppl 1):Q118.
Submit your next manuscript to BioMed Central and take full advantage of:

- Convenient online submission

- Thorough peer review

- No space constraints or color figure charges

- Immediate publication on acceptance

- Inclusion in PubMed, CAS, Scopus and Google Scholar

- Research which is freely available for redistribution

Submit your manuscript at www.biomedcentral.com/submit 